\title{
Toxin-Insensitive Ca Current in Dorsal Raphe Neurons
}

\author{
Nicholas J. Penington' and Aaron P. Fox ${ }^{2}$ \\ 'Department of Pharmacology, State University of New York, Health Science Center at Brooklyn, Brooklyn, New \\ York 11203-2098 and '2Department of Pharmacological and Physiological Sciences, University of Chicago, Chicago, \\ Illinois 60637
}

\begin{abstract}
About $54 \%$ of the whole-cell Ca current recorded in dorsal raphe neurons cannot be categorized as $\mathrm{N}$-, L-, or P-type Ca current. This current, $I_{\text {ca-Raphe, }}$ was not blocked by a combination of nimodipine, $\omega$-CgTx-GVIA, and $\omega$-AGA-IVA. Differences in toxin sensitivity and voltage dependence suggest that $I_{\text {ca-Raphe }}$ is distinct from Q- or R-type Ca currents.

In raphe neurons activation of 5- $\mathrm{HT}_{1 \mathrm{~A}}$ receptors by 5-HT inhibits $\sim 50 \%$ of the $\mathrm{Ca}$ current and slows activation. 5-HT inhibits both $\mathrm{N}$-type $\mathrm{Ca}$ channels and $I_{\text {ca-Raphe }}$ channels by $\sim \mathbf{5 0} \%$ and slows the activation of both currents to a similar extent. Other similarities between $I_{\text {Ca-Raphe }}$ and $\mathrm{N}$-type $\mathrm{Ca}$ current were observed; they are both blocked to a similar extent by $\mathrm{Ni}^{2+}$, their activation properties, their current kinetics and channel availability as a function of holding potential are almost identical. Thus, $l_{\text {Ca-Raphe }}$ represents a current that is not sensitive to known antagonists, but which is similar to $\mathrm{N}$-type $\mathrm{Ca}$ current. Although it is possible that $I_{\text {Ca-Raphe }}$ belongs to a heretofore undiscovered family of $\mathrm{Ca}$ channels it is also possible that it represents an $\omega$-CgTx GVIA-insensitive isoform of the N-type Ca channel family.

[Key words: $\mathrm{Ca}$ channels, $\mathrm{Ca}$ channel antagonists, $\omega$-conotoxin GVIA, $\omega$-AGA-IVA, $\omega$-conotoxin MVIIC, toxininsensitive Ca current]
\end{abstract}

$\alpha_{1}$ subunits of $\mathrm{Ca}$ channels when expressed in a suitable host cell produce functional $\mathrm{Ca}$ channels. Introduction of other subunits, in particular the $\beta$-subunit, increases $\mathrm{Ca}$ current amplitude and normalizes current kinetics (Lacerda et al., 1991; Varadi et al., 1991; Stea, 1993). Nonetheless, the channel pore is part of the $\alpha_{1}$ subunit. On the basis of $\alpha_{1}$ sequences, neuronal Ca channels have been divided into five distinct families. These families have been named types A-E (Catterall et al., 1993; Stea et al., 1993). At least four different functional classes of $\mathrm{Ca}$ channels have been well characterized on the basis of electrophysiological and pharmacological criteria (Llinas et al., 1989; Fox et al., 1991; Regan et al., 1991); these have been called T-, N-, L-, and P-type Ca channels. Recently, two new functional classes of $\mathrm{Ca}$ currents have been identified and named Q- and R-type Ca channels (Zhang et al., 1993). Much effort has gone into correlating the molecularly defined $\mathrm{Ca}$ channel families with the physiologically defined functional classes; at present not all of

Received Dec. 19, 1994; revised Mar. 20, 1995; accepted Apr. 4, 1995.

This work was supported by the NIH, Brain Research Foundation, and Sprague Foundation awards to A.P.F.

Correspondence should be addressed to Nicholas J. Penington, Department of Pharmacology, State University of New York, Health Science Center at Brooklyn, Box 29, 450 Clarkson Avenue, Brooklyn, NY 11203-2098.

Copyright $(C) 1995$ Society for Neuroscience $\quad 0270-6474 / 95 / 155719-08 \$ 05.00 / 0$ the data has been reconciled. A-Family clones (also called BI or $\mathrm{CaCh} 4$ ) were originally thought to encode $\mathrm{P}$-type $\mathrm{Ca}$ channels but this conclusion is now in doubt (Mori et al., 1991; Sather et al., 1993). Significant functional differences exist between A-family currents expressed in oocytes and P-type Ca channels studied in Purkinje neurons. A-Family clones produce a current that is more similar to the recently described Q-type Ca channel current (Zhang et al., 1993). B-Family clones (also called BIII, $\mathrm{CaCh} 5$, or doe-4) code for N-type Ca channels (Dubel et al., 1992; Westenbroek et al., 1992; Williams et al., 1992; Stea et a1., 1993). C- and D-family clones (also called $\mathrm{CaCh} 2$ and $\mathrm{CaCh} 3$ respectively) produce L-type (dihydropyridine-receptor) $\mathrm{Ca}$ channels. E-family clones (also called BII or doe-1) encode a current similar to R-type Ca current (Zhang et al., 1993). Interestingly, message for E-family clones is found in relative abundance throughout the CNS (Soong et al., 1993) yet R-type currents have not been found in many neurons. Where R-type currents are found they are quite small (Zhang et al., 1993).

Relatively specific antagonists have been identified for $\mathrm{N}-\mathrm{L}$-, and P-type Ca channels. Because these antagonists have shown good specificity an experimental strategy has been worked out to identify blocker-insensitive Ca currents (Mogul and Fox, 1991; Penington et al., 1991; Regan et al., 1991; Mintz et al., 1992a,b). That is, neurons are sequentially exposed to three different antagonists, $\omega$-CgTx GVIA (a specific N-type Ca channel antagonist), $\omega$-AGA-IVA [a specific P-type $\mathrm{Ca}$ channel antagonist (Llinas et al., 1989; Mintz et al., 1992b)], and a dihydropyridine (specific L-type Ca channel antagonist) until no current is left except for those that are insensitive to blockade. The efficacy of each antagonist was first identified in cells containing primarily one type of $\mathrm{Ca}$ channel. For instance, in sympathetic neurons between $80 \%$ and $90 \%$ of the current is $\mathrm{N}$-type; it is all blocked by $\omega$-CgTx GVIA (Plummer et al., 1989; Jones and Elmslie, 1992). In Purkinje neurons $>90 \%$ of the current is P-type which is blocked by $\omega$-AGA-IVA (Mintz et al., 1992b). In ventricular myocytes or skeletal muscle fibers where the vast majority of the Ca current is carried by L-type Ca currents, almost all of the current can be blocked by DHP antagonists. In neurons that contain significant quantities of L-type current, DHP antagonists are quite effective at inhibiting this current (Mogul and Fox, 1991; Scroggs and Fox, 1992). Two problems exist with this experimental strategy. In many neuronal preparations blocker-insensitive $\mathrm{Ca}$ currents are found for which no good antagonist have yet been identified making these components difficult to study. Second there are suggestions that some of the antagonist may not be as specific as originally thought (Scott et al., 1991; Sutton et al., 1993).

N-Type Ca channels ( $\alpha_{1 \mathrm{~B}}$-family) have usually been identified 
using two different criteria. First, $\mathrm{N}$ channels are potently blocked by relatively low concentrations of $\omega$-CgTx GVIA. This block is only slowly reversible. Second, channel availability at different holding potentials varies significantly. Interestingly, $\mathrm{N}$-type $\mathrm{Ca}$ channels found in chick calyx or in chromaffin cells show no such change in channel availability over a broad range of holding potentials (Stanley and Goping, 1991; Artalejo et al., 1992). Thus the second criteria while true for the majority of $\mathrm{N}$-type $\mathrm{Ca}$ channel studies, is not universal. N-Type channels have been described as having unique inactivation properties which may play a role in these differences (Plummer and Hess, 1991). The data in this manuscript show that in serotonergic dorsal raphe neurons about one-half of the whole cell Ca current is insensitive to block by the combination of nimodipine, $\omega$-CgTx, and $\omega$-AGA-IVA. This blocker-insensitive component, called $I_{\text {Ca-Raphe }}$, has a pharmacological profile different from either Q- or R-type currents (Zhang at al., 1993). $I_{\text {Ca-Raphe }}$ would normally not be identified as N-type Ca current as it is not blocked by $\omega-\mathrm{CgTx}$ GVIA. Yet many similarities exist between $I_{\mathrm{Ca} \text {-Raphe }}$ and $\mathrm{N}$-type $\mathrm{Ca}$ current. The threshold voltage for activation, the shape of the $I-V$ 's, inactivation characteristics, as well as block by $\mathrm{Ni}^{2+}$ and by 5 -HT were all similar for both $I_{\text {Ca-Raphe }}$ and $\mathrm{N}$-type $\mathrm{Ca}$ current. These results suggest that $I_{\mathrm{Ca}-\mathrm{Raphc}}$ may be due to an $\omega$-CgTx GVIA-insensitive isoform of $\mathrm{N}$-type $\mathrm{Ca}$ channel. Alternatively if $I_{\mathrm{Ca} \text {-Raphc }}$ is carried by a unique type of $\mathrm{Ca}$ channel it would argue that electrical properties are strongly conserved among different $\mathrm{Ca}$ channel families.

\section{Materials and Methods}

These results were obtained from 56 acutely isolated serotonergic DR neurons that exhibited stable $\mathrm{Ba}^{2+}$ currents of $2-4 \mathrm{nA}$ in $5 \mathrm{mM} \mathrm{Ba}{ }^{2+}$. Cells were identified as serotonergic primarily on the basis of size (see Penington et al., 1991, for details).

Cell preparation. Three coronal slices $(500 \mu \mathrm{m})$ through the brain stem at the level of the dorsal raphe nucleus were prepared from young adult rats 200-250 gm using a "vibroslice" in a manner that has previously been described (Penington et al. 1991). The slices were placed in cold ACSF containing in (mM) NaCl $119, \mathrm{KCl} 5, \mathrm{MgCl}_{2} 2, \mathrm{CaCl}_{2} 2$, $\mathrm{NaHCO}_{3} 26, \mathrm{NaH}_{2} \mathrm{PO}_{4} 1.2$ and 11 glucose, pH 7.3-7.4 when bubbled with $95 \% \mathrm{O}_{2}, 5 \% \mathrm{CO}_{2}$ ). The slices were placed on an agar base and a piece of gray matter $2 \times 2 \mathrm{~mm}$ was cut from immediately below the ccrcbral aqueduct containing the dorsal raphe nucleus. The pieces of tissue were then incubated in a PIPES buffer solution containing $0.07 \%$ trypsin (Sigma Type XI) under pure oxygen for $90 \mathrm{~min}$ according to the method of Kay and Wong (1987). The pieces of tissue were then triturated in Dulbecco's modified Eagle's medium and the isolated cells allowed to settle on a glass coverslip coated with concanavalin A. Within 5 min of plating the cells were firmly anchored to the coated coverslip.

Recording. The extracellular solution was continually perfused at a rate of about $2 \mathrm{ml} / \mathrm{min}$ into a bath containing about $1 \mathrm{ml}$ of recording solution. Neurons with truncated dendrites and a cell soma with one dimension of at least $20 \mu \mathrm{m}$ were voltage clamped using an Axopatch 1c patch-clamp amplifier in the whole cell configuration. Electrodes were coated with Sylgard and they ranged in resistance from 1.8-2.5 $M \Omega$. Leak and capacitance were subtracted from the $\mathrm{Ca}^{2+}$ current records. Leak sweeps consisted of 16 hyperpolarizing steps of $10 \mathrm{mV}$ which were then averaged. The leak sweep currents were scaled to the appropriate size and then subtracted from the individual current records. Leak sweeps were obtained at regular periods during the experiment. The voltage clamp data was filtered at $3 \mathrm{kHz}$ and then digitized at 40 , 100 , or $200 \mu \mathrm{sec}$ per point. Voltage protocols were generated and analyzed by an IBM PC 486 clone using the AXOBASIC 1 patch-clamp software and the resultant data written to disk for analysis off line. 5-HT creatine sulphate was obtained from Sigma Chemical Co. $\omega$-CgTx GVIA was purchased from Peninsula Labs. $\omega$-AGA-IVA was purchased from Peptide International. $\omega$-Conotoxin MVIIC was a kind gift of Dr. John Bell and Neurex Inc. Recordings from neurons acutely dissociated from the adult rat brain were carried out at room temperature $\left(24^{\circ} \mathrm{C}\right)$. The measurements of $\mathrm{Ca}^{2+}$ current are expressed as mean \pm SEM.

Solutions. The pipette solution used to isolate $\mathrm{Ba}^{2+}$ current through $\mathrm{Ca}^{2+}$ channels was Tris phosphate $70 \mathrm{~mm}$, Trizma base 33-EGTA 11, MgATP 2, GTP $300 \mu \mathrm{M}$, TEA-Cl 40, pH 7.3 Trizma base. The external recording solution contained TEA-Cl $135, \mathrm{BaCl}_{2} 5$, HEPES 20 , glucose $10, \mathrm{pH} 7.3$ with TEA-OH$\cdot \mathrm{NaCl}$. $\mathrm{Na}^{+}$currents were suppressed by $10^{-7}$ M TTX. $\omega$-CgTx GVIA and $\omega$-AGA-IVA were lyophilized and stored frozen. $\omega$-Conotoxin MVIIC was dissolved in a $1 \mathrm{mg} / \mathrm{ml}$ solution in water and frozen in aliquots until required. The stock solution were diluted in external solution containing $1 \mathrm{mg} / \mathrm{ml}$ cytochrome $\mathrm{C}$ and then added to the bath. $\mathrm{Ni}^{2+}$ and 5-HT were perfused into the bath. Because the bath perfusion system was quite slow a latency between application of $\mathrm{Ni}^{2+}$ or $5-\mathrm{HT}$ and the observation of an effect was always obtained (see Figs. 5, 7).

\section{Results}

\section{Raphe neurons have no $P$-, $Q$-, or R-type Ca currents}

Whole-cell recordings were carried out under conditions that effectively suppressed $\mathrm{Na}^{+}$and $\mathrm{K}^{+}$conductances by replacing all extracellular $\mathrm{Na}^{+}$with TEA, by using Tris phosphate in the patch pipette and by putting $0.1 \mu \mathrm{M}$ TTX in the bath (see Materials and Methods); $5 \mathrm{mM} \mathrm{Ba}^{2+}$ was used extracellularly. All current traces are leak subtracted. Figure $1 A$ shows currents evoked by depolarizing raphe neurons from holding potentials (HP) of $-80 \mathrm{mV}$ to a test potentials (TP) of $-10 \mathrm{mV}$. The largest current was obtained in $\mathrm{Ca}$ channel blocker free conditions (labeled "Control"). In this cell, application of $\omega$-CgTx GVIA $(1 \mu \mathrm{M})$ and nimodipine $(1 \mu \mathrm{M})$ blocked about $60 \%$ of the Ca current. $\omega$-AGA-IVA (100 nM), in the continued presence of $\omega$-CgTx GVIA and nimodipine, produced no further suppression of the current $(n=7)$ indicating that P-type Ca channels are not found in raphe neurons. Fifty nanomolar $\omega$-AGA-IVA produced a significant block of $\alpha_{1 \mathrm{~A}}$ clones (Q-type Ca current) expressed in oocytes (Sather et al., 1993); the lack of effect of $100 \mathrm{nM}$ $\omega$-AGA-IVA in raphe neurons argues against identifying $I_{\text {Ca-Raphe }}$ as Q-type Ca current. Finally, the fact that $I_{\text {Ca-Raphe }}$ did not inactivate rapidly during maintained depolarizations argues against a substantial contribution by rapidly inactivating $\mathrm{R}$-type $\mathrm{Ca}$ current.

Figure $1 B$ plots current as a function of time for the experiment shown in Figure $1 A$. $\omega$-CgTX GVIA and $\omega$-AGA-IVA were applied as indicated. No response to $\omega$-AGA-IVA was observed for the entire recording period. On average the combination of nimodipine and $\omega$-CgTx GVIA produced a $46.1 \pm$ $2.5 \%(n=28)$ inhibition of the whole-cell Ca current. [A small response to $\omega$-AGA-IVA (up to $10 \%$ ) was observed in three cells if the $\omega$-AGA IVA was added prior to any other Ca channel antagonists. In contrast no effect of $\omega$-AGA-IVA was observed if it was added after the other antagonists. We interpret this to mean that $\omega$-AGA IVA had small effects on $\mathrm{N}$ - and L-type $\mathrm{Ca}$ currents (Scoll et al., 1991; Sutton et al., 1993)]. In other experiments $\omega$-CgTx GVIA was tested at $3 \mu \mathrm{M}$ and $10 \mu \mathrm{M}$. No additional block was observed in response to higher concentrations of toxin (Penington et al., 1991).

The nonspecific high-threshold Ca channel antagonist, $\omega$-conotoxin MVIIC partially blocked $I_{\text {Ca-Raphe }}$ but not as potently as it does Q-type Ca channels (Zhang et. al. 1993). Figure $2 A$ shows current plotted as a function of time, illustrating block of $I_{\mathrm{Ca}-\mathrm{Raphc}}$ by $\omega$-conotoxin MVIIC. The largest currents were obtained in blocker free conditions. After application of $\omega$-CgTx GVIA, $\omega$-AGA-IVA and nimodipine about $50 \%$ of the current was blocked leaving $I_{\text {Ca-Raphe }}$ in isolation. Subsequent application of $\omega$-conotoxin MVIIC $(1 \mu \mathrm{M})$ blocked about $70 \%$ of the remaining 
A

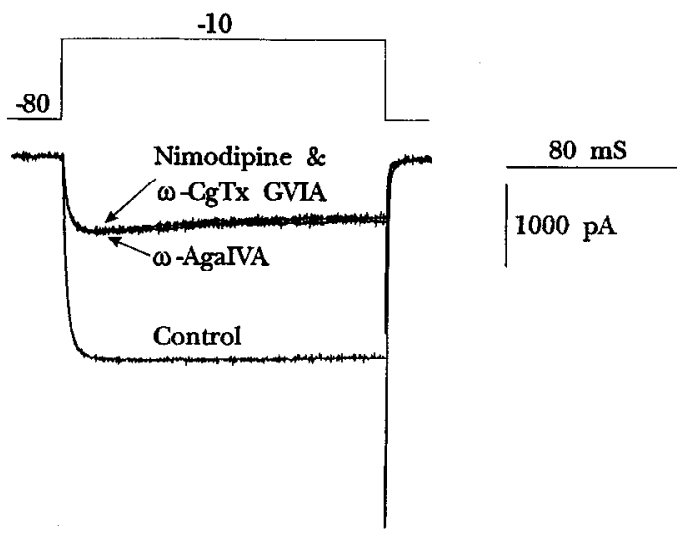

B

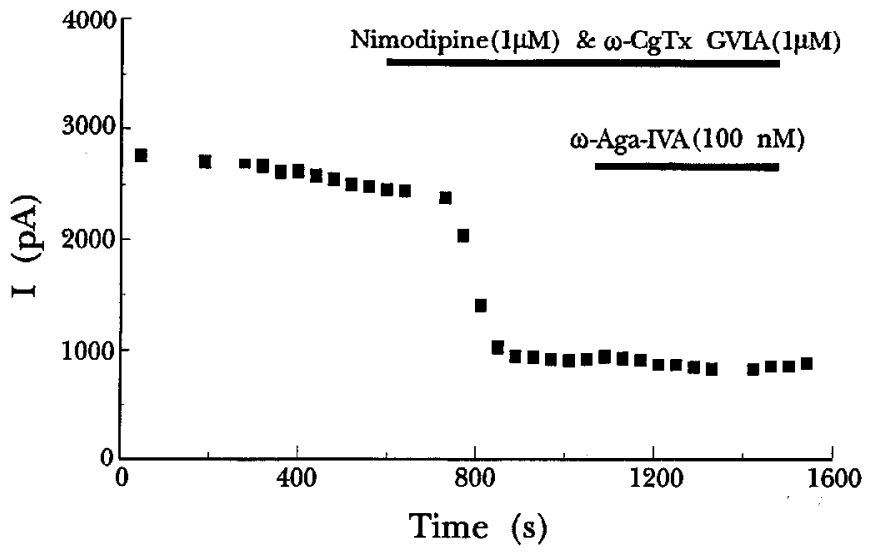

Figure I. $\omega$-AGA-IVA had no effect on the whole cell currents recorded in dorsal raphe neurons indicating that they have no P- or Q-type Ca currents. All currents shown have been leak subtracted. A, Shows currents elicited by depolarizing step from $\mathrm{HP}=-80 \mathrm{mV}$ to $-10 \mathrm{mV}$. The cell was depolarized every $20 \mathrm{sec}$. The largest current was recorded in the absence of any antagonist (labeled Control). Nimodipine $(1 \mu \mathrm{M})$ and $\omega$-CgTx $(1 \mu \mathrm{M})$ reduced the current by about $60 \%$. $\omega$-AGA-IVA (100 nM) was added in the continued presence of nimodipinc and $\omega$-CgTx GVIA. Note that the currents in the presence or absence of antagonists show little inactivation making substantial contributions by R-type $\left(\alpha_{1 \mathrm{E}}\right)$ Ca channels unlikely. $B$, plots currents, measured at -10 $\mathrm{mV}$, as a function of time. Ca channel antagonists were added as indicated in the figure. Solutions are described in the Materials and Methods.

current. This experiment shows that the onset of $\omega$-conotoxin MVIIC action was slow, taking minutes to reach steady state. Furthermore, the block was incomplete. On average $\omega$-conotoxin MVIIC $(1 \mu \mathrm{M})$ blocked $47 \%$ of $I_{\text {Ca-Raphe }}(n=8)$. These results are inconsistent with previous reports for both Q- and R-type $\mathrm{Ca}$ currents. Q-type currents are somewhat more sensitive to block by $\omega$-MVIIC (Zhang et al., 1993). In contrast, R-type currents are almost completely insensitive to block by MVIIC (Zhang et al., 1993). These results confirm that $I_{\text {Ca-Raphe }}$ is different than either Q- or R-type Ca current. Some variability was observed between experiments in the amount of block produced by $\omega$-conotoxin MVIIC. This variability opens the possibility that $I_{\text {Ca-Raphe }}$ consists of more than one Ca current component.

Interestingly, when $\omega$-conotoxin MVIIC was added after $\omega$-CgTx GVIA, $\omega$-AGA-IVA, and nimodipine $69.8 \%(n=3)$ of the total whole cell current was blocked. When $\omega$-conotoxin MVIIC was added by itself it blocked 73.9 $\pm 5 \%(n=5)$ of
A

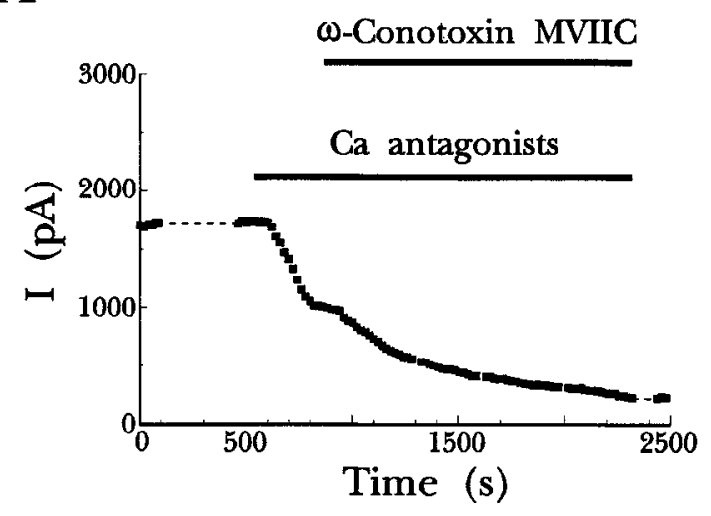

B

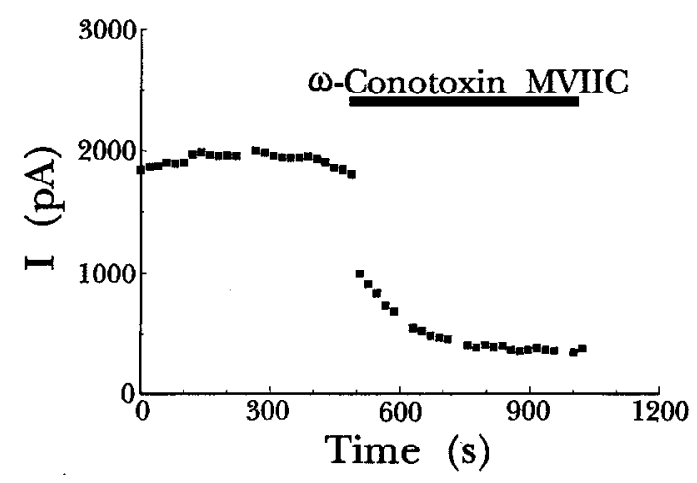

Figure 2. The Ca channel antagonist $\omega$-conotoxin MVIIC inhibits $I_{\mathrm{Ca}}$ Raphe. $A$, Plots current versus time showing that nimodipine $(1 \mu \mathrm{M})$, $\omega$-AGA-IVA (100 nM) and $\omega$-CgTx-GVIA $(1 \mu \mathrm{M})$ inhibited about 50\% of the current exposing $I_{c a-\mathrm{R}}$. Subsequent application of $\omega$-conotoxin MVIIC $(1 \mu \mathrm{M})$ blocked $-70 \%$ of $I_{\text {Ca-Raphe }}$. Onset of the block was slow. $B$, Application of $\omega$-conotoxin MVIIC inhibited the majority of the $\mathrm{Ca}$ currents found in dorsal raphe neurons. In the absence of any other antagonist $\omega$-conotoxin MVIIC blocked $\sim 80 \%$ of the whole cell current in this cell.

the total current. Figure $2 B$ shows a current-time plot where $\omega$-conotoxin MVIIC was added by itself. At first inhibition was rapid. This was followed by a slow phase of inhibition similar to that shown for $I_{\text {Ca-kaphe }}$ in Figure $2 A$. In this cell about $80 \%$ of the whole-cell current was inhibited by the toxin alone. These results suggest that $1 \mu \mathrm{M} \omega$-conotoxin MVIIC blocks $\mathrm{N}$-type $\mathrm{Ca}$ channels and $I_{\text {Ca-Raphe }}$ but not to the same extent.

Figure $3 A$ plots currents obtained before and after application of $5 \mu \mathrm{M} \omega$-conotoxin MVIIC. Even this large concentration of $\omega$-conotoxin MVIIC did not completely block $I_{\text {Ca-Raphe }}$ confirming that this component was different than Q-type $\mathrm{Ca}$ current. After scaling, it is apparent that the current kinetics after toxin application were similar to those prior to toxin application. Figure $3 B$ plots peak current as a function of time for the entire experiment. [Some cells were also exposed to $\omega$-conotoxin MVIIC $(0.5 \mu \mathrm{M})$ for long durations. After preincubating cells in toxin for $1.25 \mathrm{hr}$ the cells were then studied, in the continued presence of the toxin. The current from a holding potential of $-60 \mathrm{mV}$ averaged $363 \mathrm{pA}(n=5)$. Thus, even long-lasting exposure to toxin was not sufficient to completely inhibit $I_{\mathrm{Ca} \text {-Raphc }}$.]

$\mathrm{I}_{\text {Ca-Raphe }}$ shares functional properties with $\mathrm{N}$-type Ca channels

Channel availability as a function of holding potential has been used to distinguish between different $\mathrm{Ca}$ channels. L- and P-type 


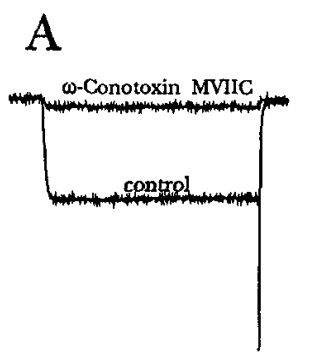

B

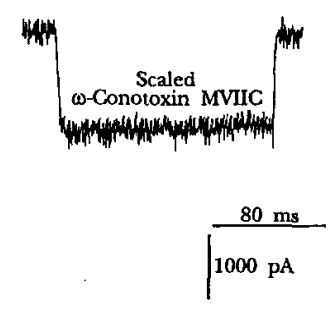

$5 \mu \mathrm{M}$ $\omega$-Conotoxin MVIC

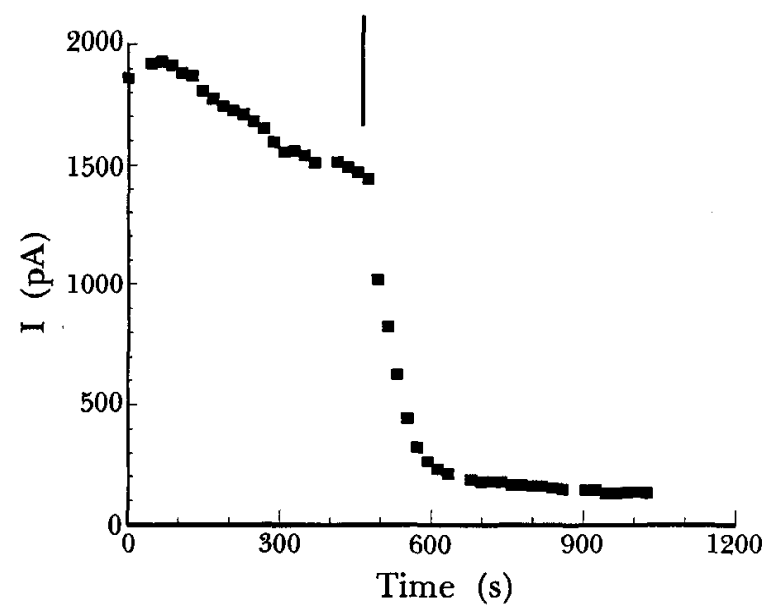

Figure 3. Extremely high concentrations of $\omega$-conotoxin MVIIC did not completely inhibit $I_{\text {Ca-Raphe }}$. $A$, Plots currents obtained with a test depolarization to $-10 \mathrm{mV}$ hefore and after the application of $5 \mu \mathrm{M}$ toxin. $B$ shows that the residual current after scaling had kinetics that were extremely similar to those of the current before toxin application. $C$ plots current amplitude as a function of time. The toxin was applied as indicated.

Ca channel availability changes little as holding potential is changed over a broad range. Plots of T-type Ca channel availability show an extremely steep availability-voltage relation. In most cells $\mathrm{N}$-type $\mathrm{Ca}$ channels have a broad and shallow avail- ability versus voltage relation (for an exception, see Artalejo et al., 1992, and Stanley and Goping, 1991). $I_{\text {CaRapho }}$ isolated with $\omega$-CgTx GVIA, nimodipine and $\omega$-Aga IVA in raphe neurons appear to share a broad and shallow availability-voltage characteristic with N-type Ca channels (Fox et al., 1987). An availability versus voltage curve $\left(H_{\infty}\right)$ was constructed by varying the holding potential while keeping constant the test potential at $-10 \mathrm{mV}$. Data used to construct the availability curve is shown in Figure $4 A$, which plots current versus time as the holding potential was changed. A period $\geq 2 \mathrm{~min}$ for each holding potential was required for availability to stabilize. After pooling data from eight cells the $H_{\infty}$ graph shown in Figure $4 B$ was constructed. The availability curve was fit with a Boltzmann function ( $V_{1 / 2}$ of $60.2 \mathrm{mV}$ and a slope value of 15.24). The shallow slope value is characteristic of N-type channels (Fox et al., 1987). [These results are not due to increasing efficacy of nimodipine block at depolarized holding potentials as raphe neurons have few L-type Ca channels (Penington et al., 1991). Thus, when nimodipine is used by itself little block is seen even at depolarized holding potentials].

Blockade of $\mathrm{Ca}$ channels by inorganic ions can sometimes provide a method for elucidating differences between permeation properties of $\mathrm{Ca}$ channels. $\mathrm{Ni}^{2+}$ has proved to be particularly useful in distinguishing among various classes of $\mathrm{Ca}$ channels. Figure 5 shows a current-time plot that illustrates $\mathrm{Ni}^{2+}$ block; application of $\mathrm{Ni}^{2+}(50 \mu \mathrm{M})$ blocked about $50 \%$ of the wholecell current. After washing the $\mathrm{Ni}^{2+}$ out of the bath, subsequent addition of $\omega$-CgTx, AGA and nimodipine blocked about $50 \%$ of the current and isolated $I_{\text {Ca-Raphe }}$. Under these conditions, $\mathrm{Ni}^{2+}$ blocked about $50 \%$ of $I_{\text {Ca-Raphe }}$. Thus, about the same percentage of the $\mathrm{Ca}$ current was blocked by $\mathrm{Ni}^{2+}$ before or after the $\mathrm{Ca}$ channel blocker mixture ( $\omega$-CgTx GVIA, $\omega$-AGA IVA, and nimodipine), indicating similar sensitivity to the inorganic blocker. On average $50 \mu \mathrm{M} \mathrm{Ni}{ }^{2+}$ blocked $47.3 \%(n=3)$ of the Ca current prior to application of the antagonist mixture and $48.8 \pm 3(n$ = 5) after application. The Ca current blocked by the antagonist mixture is primarily $\mathrm{N}$-type $\mathrm{Ca}$ current suggesting that block of $I_{\text {Ca-Raphe }}$ by $\mathrm{Ni}^{2+}$ is quite similar to that of $\mathrm{N}$-type Ca channels.

The voltage dependence of activation for $I_{\mathrm{Ca}-\text { Raphe }}$ was similar to that of N-type Ca channels. Figure $6 \mathrm{~A}$ plots current-voltage
Figure 4. Plot of channel availability versus voltage for $I_{\mathrm{Ca} \text {-Raphe }}$ are similar to those of N-type Ca channels. A, Plots changes in $I_{\text {Ca-Raphe }}$ amplitude as the holding potential was changed. Nimodipine, $\omega$-AGA-IVA, and $\omega$-CgTx GVIA were used to isolate $I_{\text {Ca-Raphe }}$. The holding potentials were changed as indicated in the figure. Each holding potential was maintained for $>3 \mathrm{~min}$ to allow the currents to reach their steady state values. The test potential was always to $-10 \mathrm{mV}$. Inset plots representative current traces at each holding potential. $B$, The peak currents recorded were normalized relative to peak current recorded at $-100 \mathrm{mV}\left(I_{\max }\right)$. The data at each holding potential was then divided by the current at $-100 \mathrm{mV}$. By definition the current at HP $=-100$ $\mathrm{mV}$ was equal to 1 . The resulting availability-voltage relation $\left(H_{\infty}\right)$ was fitted with a Boltzmann function: $I / I_{\max }=$ $1 /[1+\exp ([V+60.2] / 15.245)]$.
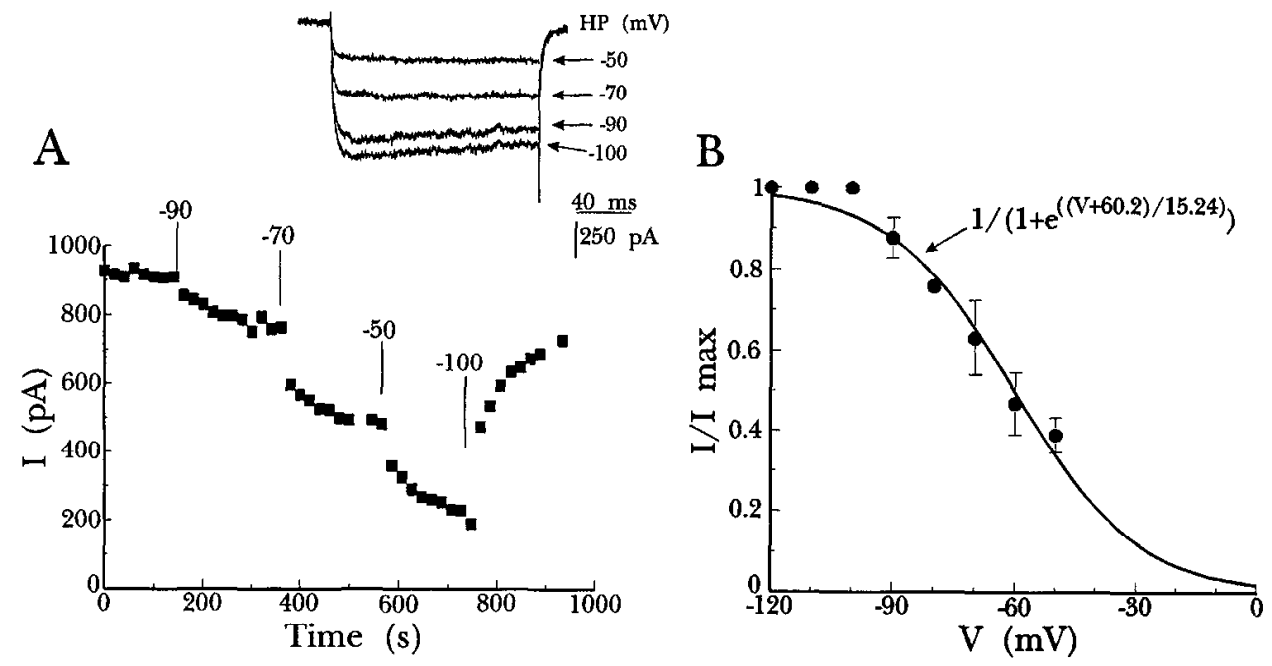


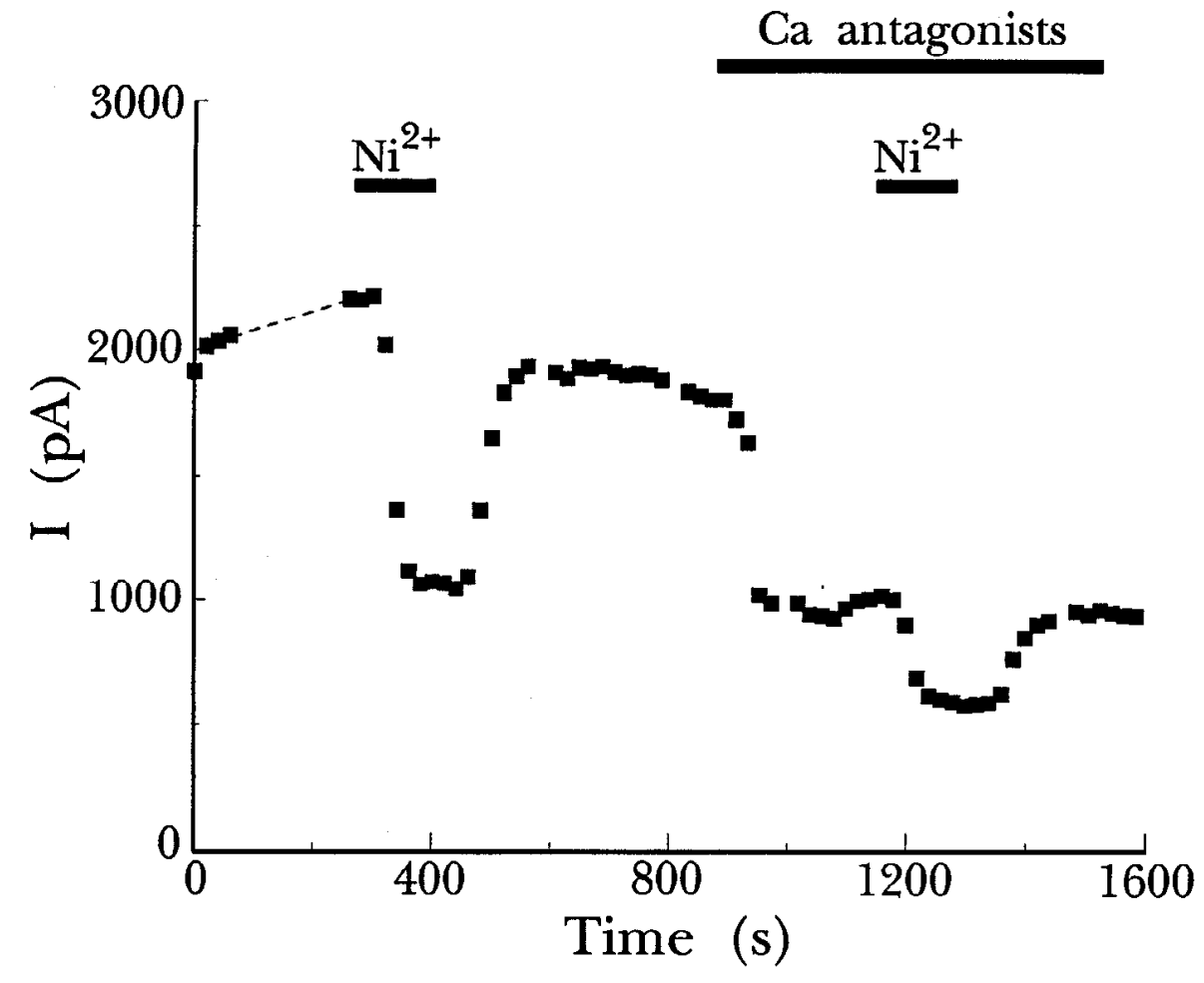

A Unscaled

B

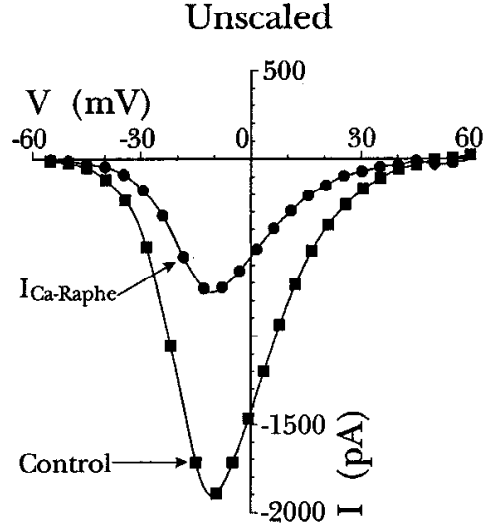

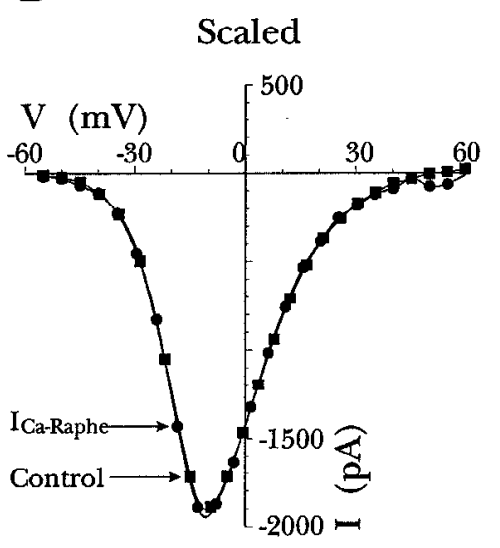

C

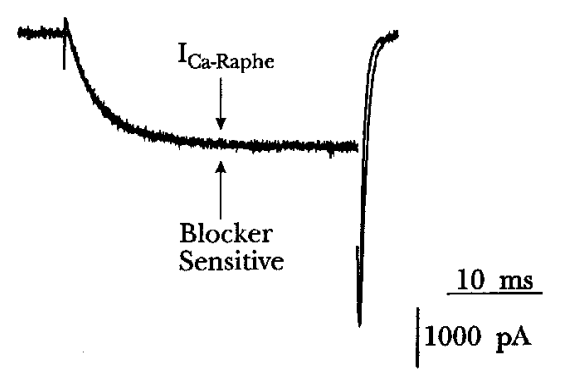

Figure 5. $\mathrm{Ni}^{2+}(50 \mu \mathrm{M})$ inhibits onehalf of the total whole-cell current and of $I_{\text {Ca-Raphe }}$. The figure shows a plot of current versus time. $\mathrm{Ni}^{2+}$ was added as indicated and blocked one-half of the current. Nimodipine, $\omega$-AGA-IVA, and $\omega-\mathrm{CgTx}$ were added to the bath (labeled $\mathrm{Ca}$ antagonists) and blocked $-50 \%$ of the current exposing $I_{\text {Ca-Raphe. }}$. Subsequent application of $\mathrm{Ni}^{2+}$ in the continued presence of the other antagonists blocked one-half of $I_{\text {Ca-Raphe }}$.
Figure 6. The voltage dependence and current kinetics of $I_{\mathrm{Ca} \text {-Raphe }}$ are similar to that of N-type Ca currents. $A$, Plots current as a function of voltage $(I-V)$. The largest currents were obtained in blocker free conditions (labeled Control). Application of nimodipine, $\omega$-AGA-IVA, and $\omega$-CgTx GVIA inhibited $\sim 65 \%$ of the current (smallest $I-V$ curve labeled $I_{\text {Ca-Raphe }}$ ). Note that the $I-V$ curves were corrected for series resistance errors. By fitting the capacitance transient of small hyperpolarizing steps we calculated that $2.036 \times 10^{-13}$ Coulombs were required to charge the membrane capacitance for a $10 \mathrm{mV}$ step. Thus the cell capacitance was $\sim 20 \mathrm{pF}$. After compensation we calculate from a $60 \mu \mathrm{sec}$ time constant that the series resistance was 3 $\mathrm{M} \Omega$ In this experiment errors between 5-6 $\mathrm{mV}$ were possible. $I-V$ curves were fit with a cubic spline function. $B$, The $I_{\text {Ca-Ranhe }} I-V$ was scaled to the same size as the Control $I-V$ to compare activation threshold and $I-V$ shape. $C$, $I_{\text {Ca-Raphe }}$ current records were obtained in the presence of the Ca channel blockers. Subtracting $I_{\text {Ca-Raphe }}$ currents from the currents obtained in blocker free conditions yielded the blocker-sensitive currents. These currents were then scaled to be the same amplitude as those of $I_{\text {Ca-Raphe }}$. Note that the currents prior to subtraction were obtained at potentials that were different from each other by $\sim 3 \mathrm{mV}$. 
relations $(I-V)$ obtained from a holding potential of $-60 \mathrm{mV}$ to eliminate possible contamination by a small component of T-type $\mathrm{Ca}$ current. The largest $I-V$ was obtained under blocker free conditions ("Control"). The smallest $I-V$ represents $I_{\text {Ca-Raphe }}$ currents obtained after application of the $\mathrm{Ca}$ channel antagonist mixture. Figure $6 B$ shows the $I_{\text {Ca-Raplic }} I-V$ scaled to the same size as the control $I-V$. Note that the threshold for activation is very similar as is the shape of the $I-V$. These $I-V$ 's were corrected for small voltage shifts due to series resistance errors (see Fig. 6 caption for details). Figure $6 C$ shows $I_{\text {Ca-Raphe }}$ currents scaled to the same size as the blocker-sensitive currents, obtained by subtracting $I_{\text {Ca-Raphe }}$ currents from the "Control" current. Note that the currents look virtually identical. Thus, activation and kinetic properties of the $I_{\text {Ca-Raphe }}$ were similar to the blocker-sensitive currents which are primarily $\mathrm{N}$-type $\mathrm{Ca}$ currents. This was true at every test potential (data not shown). These data show that the threshold for activation, $I-V$ shape, and current kinetics of $I_{\text {Ca-Raphc }}$ were similar to those of the $\mathrm{N}$-type Ca channels.

5-HT inhibited whole-cell $\mathrm{Ca}$ currents in DR neurons and slowed activation. This response is mediated by $5-\mathrm{HT}_{1 \mathrm{~A}}$ receptors (Penington and Kelly, 1990; Penington et al., 1991). Similar to other inhibitory neurotransmitters, the response to $5-\mathrm{HT}$ is voltage dependent (Penington et al., 1991). Figure $7 A$ plots the response to 5-HT before and after application of the Ca channel antagonist mixture. It shows that 5 -HT blocked about $50 \%$ of the current before or after application of the antagonist mixture indicating that $I_{\text {Ca-Raphe }}$ had a similar sensitivity to $5-\mathrm{HT}$ as did $\mathrm{N}$-type $\mathrm{Ca}$ channels. On average 5 -HT blocked $47.4 \pm 3 \%(n$ - 12) of the Ca current prior to application of the antagonist mixture and $43.9 \pm 2.4 \%$ after application of the antagonist mixture. Note that in both cases the currents were slowed to a similar extent.

5-HT was less effective at inhibiting Ca currents when it was applied after application of $\omega$-conotoxin MVIIC. Figure $7 B$ plots data from an experiment where 5-HT blocked $18 \%$ of the current in the presence of $\omega$-conotoxin MVIIC. Prior to toxin application 5-HT inhibited $47 \%$ of the current. On average 5-HT only blocked $18.9 \%$ of the current when it was added after the toxin $(n=3)$; in these same three cells 5-HT inhibited $35.4 \%$ of the current prior to application of $\omega$-conotoxin MVIIC.

\section{Discussion}

Dorsal raphe neurons have small components of L- and T-type $\mathrm{Ca}$ currents on the basis of pharmacological and electrophysiological studies (Penington et al., 1991). Raphe neurons have no $\omega$-AGA-IVA-sensitive currents suggesting they have no P-type $\mathrm{Ca}$ channels. To a reasonable approximation the 5-HT-sensitive raphe neuron $\mathrm{Ca}$ currents can be subdivided into two components. They are $\mathrm{N}$-type $\mathrm{Ca}$ current and a second component which we have named $I_{\text {Ca-Raphe. }}$. Three questions immediately present themselves. First, is $I_{\text {Ca-Raphe }}$ similar to any functionally or molecularly defined family of Ca channels? Second, is $I_{\text {Ca-Raphe }}$ composed of one or several types of Ca channels? Third, what are the properties of $I_{\text {Ca-Raphe }}$ in relation to other toxin-resistant Ca currents? Although definitive answers to these questions will require further work, the experiments in this paper directly address these issues.

Perhaps the simplest of the threc questions to resolve is whether $I_{\text {Ca-Raphc }}$ is similar to any known Ca currents/channels. It is clearly not a member of L-type Ca channel family as it is not sensitive to dihydropyridines and is quite sensitive to changes
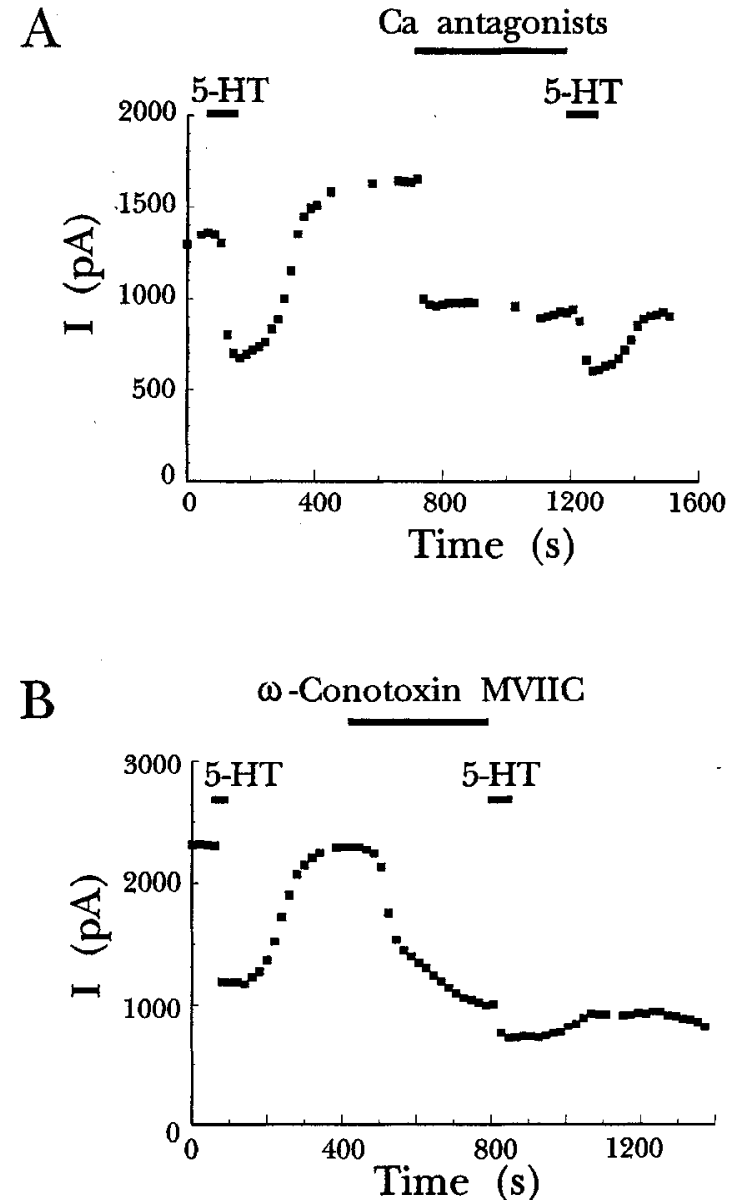

Figure 7. 5-HT inhibits $I_{\text {Ca-Raphe }}$ and N-type Ca current in a similar manner in dorsal raphe neurons. Plot of current versus time. 5-HT (1 $\mu \mathrm{M})$ was added as indicated and it inhibited $\sim 50 \%$ of the whole cell current. Subsequent application of nimodipine, $\omega$-AGA-IVA and $\omega$-CgTx GVIA inhibited $\sim 45 \%$ of the current. Under these conditions, which expose $I_{\text {Ca-Raphc }}$, reapplication of 5 -HT still produced $\sim 50 \%$ inhibition. $B$, Responses to $5-\mathrm{HT}$ were diminished but still present even after application of 6 -conotoxin MVIIC.

in holding potential. This lets us rule out $\alpha_{1 \mathrm{C}}$ and $\alpha_{\mathrm{ID}}$ as being involved in the generation of $I_{\mathrm{Ca} \text {-Raphe}}$.

Originally $\alpha_{1 \mathrm{~A}}$ was thought to code for P-type Ca channels. Message for $\alpha_{\text {IA }}$ was found throughout the CNS, including in locations thought to express primarily P-type Ca channels. Notable differences exist between $\alpha_{1 \mathrm{~A}}$ currents in oocytes and P-type Ca currents studied in Purkinje neurons. Sensitivity to $\omega$-AGA-IVA, a specific P channel antagonist, is about 10 fold lower for $\alpha_{1 \mathrm{~A}}$ coded channels. $\alpha_{1 \mathrm{~A}}$ currents inactivate during maintained depolarizations while P-type Ca channels show little inactivation during depolarization. A recently identified current component, called Q-type, has many similarities to $\alpha_{1 \mathrm{~A}}$ currents. Is $I_{\text {Ca-Raphe }}$ similar to $\alpha_{1 \mathrm{~A}} / \mathrm{Q}$-type Ca current? We suspect they are not the same for several reasons. First, $50 \mathrm{nM} \omega$-AGA-IVA is somewhat effective at blocking $\alpha_{1 \mathrm{~A}}$ currents (Sather et al., 1993). In contrast, $100 \mathrm{nM} \omega$-AGA-IVA has no effect on $I_{\text {Ca-Raphe }}$. Second, activation of $\alpha_{1 \mathrm{~A}}$ is an extremely steep function of voltage. $I_{\text {Ca-Raphe }}$ shows a less steep $I-V$ relation. Finally, $I_{\text {Ca-Raphe }}$ seems less susceptible to block by $\omega$-conotoxin MVIIC. Even after long preincubations with $0.5 \mu \mathrm{M} \omega$-conotoxin MVIIC it did not block all of $I_{\text {Ca-Raphe }}$ nor could concentrations as high as $5 \mu \mathrm{M}$. The differences between $I_{\mathrm{Ca}-\mathrm{Raphe}}$ and $\alpha_{1 \mathrm{~A}} / \mathrm{Q}$ may be subject to rein- 
terpretation when more information regarding $\alpha_{1 \mathrm{~A}} / \mathrm{Q}$-type currents becomes available.

$I_{\text {Ca-Raphe }}$ is not similar to $\alpha_{\mid \mathrm{E}} / \mathrm{R}$-type Ca current for two reasons. First, $\alpha_{1 \mathrm{E}} / \mathrm{R}$-type $\mathrm{Ca}$ currents inactivate rapidly during maintained depolarizations; $I_{\text {Ca-Raphe }}$ does not. Second, $I_{\text {Ca-Raphe }}$ is partially blocked by $\omega$-conotoxin MVIIC. R-type Ca channels are almost completely insensitive to this toxin.

$I_{\text {Ca-Raphe }}$ is unlike T-type Ca current because it does not inactivate rapidly and it is much less sensitive to changes in holding potential than are T-type $\mathrm{Ca}$ channels. Finally, T-type Ca currents are truly low-threshold; they activate at much more negative potentials than does $I_{\text {Ca-Raphe }}$.

The final question to resolve is whether $I_{\text {Ca-Raphe }}$ is similar to $\mathrm{N}$-type Ca currents. A priori any current that does not respond to the N-type $\mathrm{Ca}$ channel antagonist $\omega$-CgTx GVIA would be classified as non-N-type (Fox et al., 1991), but we feel that analysis may be too superficial. While the difference in toxin sensitivity between $I_{\text {Ca-Raphe }}$ and $\mathrm{N}$-type Ca channels is undoubtedly true, it is also true that they share many of the same characteristics. 5-HT inhibits both $\mathrm{N}$-type Ca channels and $I_{\text {Ca-Raphe }}$ channels by $\sim 50 \%$ and slows the activation of both currents to a similar extent. $I_{\text {Ca-Raphc }}$ and N-type Ca current are both blocked to a similar extent by $\mathrm{Ni}^{2+}$. Their activation properties, their current kinetics and channel availability as a function of holding potential are very similar as well. Thus functionally, $I_{\text {Ca-Raphe }}$ resemble N-type Ca current to a large extent.

We have not studied extensively whether $I_{\text {Ca-Raphe }}$ is composed of one or several different types of Ca channels. Nonetheless, if it is composed of several different channels it is most likely that one type predominates. There was no good evidence in either the $H_{\infty}$ curves or in antagonist sensitivity for multiple components. Even so, our data does not unambiguously resolve this issue. Successful resolution of this issue will require new classes of antagonists.

Comparisons to other $\mathrm{Ca}$ channel antagonist resistant $\mathrm{Ca}$ currents are quite difficult. These components have becn described using a variety of techniques in many preparations (Mogul and Fox, 1991; Regan et al., 1991; Scroggs and Fox, 1992). The main problem is that the toxin-insensitive components have not been studied in sufficient detail in most preparations to allow direct comparisons to $I_{\mathrm{Ca} \text {-Raphe }}$. Other toxin-insensitive Ca currents are observed in experiments that measure neurotransmitter release or $\mathrm{Ca}^{2+}$ influx. Interestingly, $\omega$-CyTx GVIA, the $\mathrm{N}$ channel toxin only partially blocks transmitter release or $\mathrm{Ca}^{2+}$ influx at several mammalian synapses (Yoshikami et al., 1988; Hillyard et al., 1992; Takahashi and Momiyama, 1993). $\omega$-Conotoxin MVIIC (from Conus magus) which blocks a variety of high threshold $\mathrm{Ca}$ channels was more effective at preventing $\mathrm{Ca}^{2+}$ influx in synaptosomal preparations (Hillyard et al., 1992). $\omega$-AGA IVA (from funnel web spider venom) which blocks P-type Ca channels (Mintz et al., 1992b) is also capable of blocking release from synapses unaffected or incompletely blocked by $\omega$-CgTx GVIA (Takahashi and Momiyama, 1993).

Do the channels that carry $I_{\text {Ca Raphe }}$ current represent an entirely new family of $\mathrm{Ca}$ channels with properties similar to those of $\mathrm{N}$-type Ca channels, or are they simply $\omega$ - CgTx GVIA-insensitive N-type Ca channels? Because dorsal raphe neurons express "standard" N-type Ca channels as well as $I_{\text {Ca-Raphe, }}$, it seems that the cells can process $\alpha_{1 \mathrm{~B}}$ transcripts correctly, suggesting that $I_{\text {Ca-Raphe }}$ is unlikely to be due to a processing defect in the raphe neurons. The second possibility mentioned above can be further split into two. $\mathrm{Ca}$ channels are multisubunit proteins; thus, a unique subunit combination with the identical $\alpha_{1 \mathrm{~B}}$ subunit could give rise to toxin-insensitive $N$ channels. Even though it may be true that only the $\alpha_{1 \mathrm{~B}}$ subunit is required to confer $\omega$-CgTx GVIA sensitivity on $\mathrm{Ca}$ currents it may also be true that other subunits can affect that sensitivity. Alternatively, $I_{\text {Ca-Raphe }}$ may represent an $\omega$-CgTX GVIA-insensitive isoform of the $\alpha_{1 \mathrm{~B}}$ family. Further experimentation will be required to distinguish between these three possibilities. These ongoing studies may also help explain toxin-insensitive synaptic transmission observed frequently in the CNS.

\section{References}

Artalejo CR, Perlman RL, Fox AP (1992) w-Conotoxin GVIA blocks a $\mathrm{Ca}^{2+}$ current in bovine chromaffin cells that is not of the "Classic" $\mathrm{N}$ type. Neuron 8:85-95.

Catterall WA, de Jongh K, Rotman E, Hell J, Westenbroek R, Dubel SJ, Snutch TP (1993) Molecular properties of calcium channels in skeletal muscle and neurons. Ann NY Acad Sci 681:342-355.

Dubel SJ, Starr TV, Hell J, Ahlijanian MK, Enyeart JJ, Catterall WA, Snutch TP (1992) Molecular cloning of the $\alpha-1$ subunit of an $\omega$-conotoxin-sensitive calcium channel. Proc Natl Acad Sci USA 89:50585062.

Fox AP, Nowycky MC, Tsien RW (1987) Kinetic and pharmacological properties distinguish three types of calcium currents in chick sensory neurons. J Physiol (Lond) 394:149-172.

Fox AP, Hirning LD, Mogul D, Artalejo CR, Penington NJ, Scroggs RS, Miller RJ (1991) Modulation of calcium channels by neurotransmitters, hormones and second messengers. In: Calcium channels: their properties, functions, regulation, and clinical relevance (Hurwitz L, Partridge LD, Leach JK, eds). Boca Raton, FL: CRC.

Hillyard DR, Monje VD, Mintz IM, Bean BP, Nadasdi L, Ramachandran J, Miljanich G, Azimi-Zoonooz A, McIntosh JM, Cruz LJ, Imperial JS, Olivera BM (1992) A new Conus peptide ligand for mammalian presynaptic $\mathrm{Ca}^{2+}$ channels. Neuron 9:69-77.

Jones SW, Elmslie KS (1992) Separation and modulation of calciunn currents in bullfrog sympathetic neurons [review]. Can J Physiol Pharmacol [Suppl] 70:S56-63.

Kay AR, Wong RKS (1987) Calcium current activation kinetics in isolated pyramidal neurones of the CA1 region of the mature guineapig hippocampus. J Physiol (Lond) 392:602-616.

Lacerda AE, Kim HS, Ruth P, Perez-Reyes E, Flockerzi V, Hofmann F, Birnbaumer L, Brown AM (1991) Normalization of current kinetics by interaction between the $\alpha 1$ and $\boldsymbol{\beta}$ subunits of the skeletal muscle dihydropyridine-sensitive $\mathrm{Ca}^{2+}$ channel. Nature 352:527-530.

Llinas R, Sugimori M, Cherksey B (1989) Voltage dependent calcium conductances in mammalian neurons: the P channel. Ann NY Acad Sci 560:103-111.

Mintz IM, Adams ME, Bean BP (1992a) P-Type calcium channels in rat central and peripheral neurons. Neuron 9:85-95.

Mintz IM, Venema VJ, Swiderek KM, Lee TD, Bean BP, Adams ME (1992b) P-type calcium channels blocked by the spider toxin $\omega$-AgaIVA. Nature 355:827-829.

Mogul DJ, Fox AP (1991) Characterization Of Ca channels in Acutely isolated hippocampal CA3 pyramidal neurons: evidence For multiple types of Ca channels. J Physiol (Lond) 433:259-281.

Mori Y, Friedrich T, Kim MS, Mikami A, Nakai J, Ruth P, Bosse E, Hofmann F, Flockerzi V, Furuichi T, Mikoshiba K, Imoto K, Tanabe T, Numa S (1991) Primary structure and functional expression from complementary DNA of a brain calcium channel. Nature 350:398402.

Penington NJ, Kelly JS (1990) Serotonin receptor activation reduces calcium current in an acutely dissociated adult central neuron. Neuron 4:751-758.

Penington NJ, Kelly JS, Fox AP (1991) A study of the mechanism of $\mathrm{Ca}^{2+}$ current inhibition produced by serotonin in dorsal raphe neurons. J Neurosci 11:3594-3609.

Plummer MR, Hess P (1991) Reversible uncoupling of inactivation in N-type calcium channels. Nature 351:657-659.

Plummer MR, Logothetis DE, Hess P (1989) Elementary properties and pharmacological sensitivities of calcium channels in mammalian peripheral neurons. Neuron 2:1453-1463.

Regan LJ, Sah DW, Bean BP (1991) $\mathrm{Ca}^{2+}$ channels in rat central and 
peripheral neurons: high-threshold current resistant to dihydropyridine blockers and $\omega$-conotoxin. Neuron 6:269 280 .

Sather WA, Tanabe T, Zhang JF, Mori Y, Adams ME, Tsien RW (1993) Distinctive biophysical and pharmacological properties of class A (BI) calcium channel $\alpha 1$ subunits. Neuron 11:291-303.

Scott RH, Pearson HA, Dolphin AC (1991) Aspects of vertebrate neuronal voltage-activated calcium currents and their regulation. Prog Neurobiol 36:485-520.

Scroggs RS, Fox AP (1992) Variation of $\mathrm{Ca}^{2+}$ channel expression in acutely isolated adult dorsal root ganglion neurons of different sizes. J Physiol (Lond) 445:639-658.

Soong TW, Stea A, Hodson CD, Dubel SJ, Vincent SR, Snutch TP (1993) Structure and functional expression of a member of the low voltage-activated calcium channel family. Science 260:1133-1136.

Stanley EF, Goping G (1991) Characterization of a calcium current in a vertebrate cholinergic presynaptic nerve terminal. J Neurosci 11: 985-993.

Stea A, Dubel SJ, Pragnell M, Leonard JP, Campbell KP, Snutch TP (1993) A beta-subunit normalizes the electrophysiological properties of a cloned $\mathrm{N}$-type $\mathrm{Ca}^{2+}$ channel $\alpha 1$-subunit. Neuropharmacology 32 : $1103-1116$.

Sutton KG, Pearson HA, Scott RH, Dolphin AC (1993) Inhibition of
$\mathrm{Ca}^{2+}$ channel currents in cultured rat cerebellar granule neurones by the funnel web spider toxin $\omega$-agatoxin IVA. J Physiol (Lond) 467: 271P.

Takahashi T, Momiyama A (1993) Different types of Ca channels mediate central synaptic transmission. Nature 366:156-158.

Varadi G, Lory P, Schultz D, Varadi M, Schwartz A (1991) Acceleration of activation and inactivation by the beta subunit of the skeletal muscle calcium channel. Nature 352:159-162.

Westenbroek RE, Hell JW, Warner C, Dubel SJ, Snutch TP, Catterall WA (1992) Biochemical properties and subcellular distribution of an N-type calcium channel $\alpha 1$ subunit. Neuron 9:1099-1115.

Williams ME, Brust PF, Feldman DH, Patthi S, Simerson S, Maroufi A, McCue AF, Velicelebi G, Ellis SB, Harpold MM (1992) Structure and functional expression of an $\omega$-conotoxin-sensitive human $\mathrm{N}$-type calcium channel. Science 257:389-395.

Yoshikami D, Bagabaldo Z, Olivera BM (1989) The inhibitory effects of omega-conotoxins on $\mathrm{Ca}$ channels and synapses. Ann NY Acad Sci 560:230-248.

7hang IF, Randall AD, Fllinor PT, Horne WA, Sather WA, Tanabe T, Schwarz TL, Tsien RW (1993) Distinctive pharmacology and kinetics of cloned neuronal $\mathrm{Ca}^{2+}$ channels and their possible counterparts in mammalian CNS neurons. Neuropharmacology 32:10751088 